\section{Os deuses que dançam em São Paulo}

Reginaldo PRANDI. Mitologia dos orixás. São Paulo, Companhia das Letras, 2001. 624 páginas.

\section{Monique Augras}

Este livro estava fazendo falta. Nele, Reginaldo Prandi, conhecido especialista do campo afrobrasileiro, nos apresenta uma soma de mitos ilustrativos da significação de cada um dos orixás que hoje dançam nos terreiros brasileiros. Consegue harmonizar erudição e recriação poética ao transcrever, em poemas de versos livres, histórias recolhidas ao longo da pesquisa de campo e lendas encontradas nos textos dos estudiosos.

A obra se situa, por assim dizer, na dobradiça que une tradição religiosa e produção acadêmica, transmissão oral e registro escrito. Assim fazendo, Reginaldo Prandi toma clara posição entre os autores que, sem deixar de homenagear o valor e o peso das referências africanas, vêem o candomblé como uma religião em franca expansão e permanente transformação, na qual novos mitos e ritos podem estar surgindo e merecem o registro, com a mesma legitimidade que outrora - em evidente ilustração da permanência, entre os cientistas sociais, do "ídolo das origens", como dizia Marc Bloch - se atribuía exclusivamente às "raízes africanas".

A questão das fontes das informações compiladas pela equipe coordenada por Prandi ao longo de vários anos é por ele tratada com peculiar sutileza, ao referir-se ao material proveniente dos cadernos redigidos por iniciados de alta patente. Esses cadernos continham recomendações referentes aos diversos rituais de oferenda, bem como a narrativa dos mitos que lhes davam sustento. Ainda que sempre aludidos de forma mais ou menos sigilosa, há muito tempo circulavam entre os terreiros e parte do seu conteúdo há muito também já havia sido publicada por diversos pesquisadores. É com muito tato e delicadeza que o autor se esforça em situar os empréstimos - nem sempre claramente assumidos - e deslindar os caminhos ao longo dos quais os ensinamentos de uma das mais ilustres mães-de-santo da Bahia se foram transmitindo e transformando. Tal sutileza, diga-se de passsagem, faz também parte do estilo próprio do povo-de-santo, apreciador de comentários intrigantes sobre a fundação dos terreiros, o comportamento dos seus dignitários e a constituição das famílias-de-santo.

O livro pode ser lido, portanto, em vários níveis. Primeiro, o acadêmico, com o levantamento quase exaustivo dos autores que transcreveram mitos referentes aos orixás na Nigéria, no Benin, em Cuba e no Brasil. Cada mito relatado no corpo do texto remete a uma nota que, no fim do volume, analisa criticamente as fontes e as diversas versões. Do mesmo modo, as fontes orais são minuciosamente estipuladas, bem como a identificação dos terreiros de São Paulo onde foi realizado o trabalho de campo. Um glossário completa a informação etnológica.

Mas pode ser visto também como uma tentativa, particularmente bem-sucedida, de divulgação de importante vertente da cultura brasileira. Para o público mais amplo, "mitologia" remete quase que exclusivamente à mitologia grega, ou romana. Os dicionários de alcance geral reforçam essa percepção: "Mitologia: História fabulosa dos deuses, semideuses e hérois da Antiguidade." (Pequeno Dicionário Brasileiro da Língua Portuguesa, São Paulo, Abril Cultural, 1971). É, claramente, da "Antiguidade" clássica que se trata, a verdadeira, a que legitima a cultura ocidental... Quantas vezes, ao ministrar alguma palestra para pessoas esclarecidas da boa sociedade, não ouvi a observação maravilhada mas um tanto perplexa: "Mas é tão bonito quanto os Gregos!”. É tão bonito quanto, é verdade. E não será um dos menores méritos de Reginaldo Prandi o de apresentar, sob forma literária, sem dúvida mais palatável do que os nossos costumeiros tratados de Antropologia, uma soma tão extensa e completa das lendas dos orixás.

Em sua avaliação aguda e crítica do papel dos pesquisadores em relação ao seu campo de investigação, Roberto Motta costuma sublinhar que nós, os acadêmicos, somos os teólogos dessa religião de transmissão oral e que os mitos transcritos e organizados por nós não deixam de ser, em certo 
sentido, obra nossa. Mas não podemos esquecer que a própria mitologia grega, tal como a conhecemos, tampouco retrata o nível cotidiano e concreto dos rituais, ou as crenças vivenciadas por sacerdotes e devotos. O que temos são obras de intelectuais, poetas e autores trágicos, que deram forma ao material que os rodeavam e, provavelmente, o interpretaram. Daí a sua forma acabada e a coerência do seu conteúdo. Mutatis mutandis, algo parecido pode ser dito a favor do empreendimento de Reginaldo Prandi. É obra de um intelectual, de um cientista social, mas é também, assumidamente, uma produção poética, nas entrelinhas da qual é também permitido perceber os ecos de uma vivência religiosa.

E tal como já tivemos todos a oportunidade de verificar, o campo não se mantém passivo diante da nossa produção. Sabe muito bem utilizála em proveito de sua sobrevivência no seio da sociedade mais ampla. Há um diálogo constante entre pesquisadores e pesquisados e, além do mais, como bem o sublinha o autor, o povo-desanto se move doravante dentro do mundo do escrito, com livros publicados por sacerdotes e sacerdotisas. A mitologia aqui organizada e formatada terá, sem dúvida, certa influência sobre a maneira como, daí por diante, será transmitido para os noviços o acervo do "conhecimento necessário para o desvendamento dos mistérios sobre a origem e o governo do mundo dos homens e da natureza, sobre o desenrolar do destino dos homens, das mulheres e das crianças e sobre os caminhos de cada um na luta cotidiana contra os infortúnios.” (p. 17).

É portanto um mundo reencantado que o livro apresenta, e o encantamento se expressa também no plano visual, pois a transcrição dos mitos vem precedida de um ensaio fotográfico que introduz o leitor no mundo dos deuses que dançam. Tal como o texto, a parte iconográfica pode ser entendida em vários níveis: o do simples deleite - o interesse estético sempre me pareceu um aspecto relevante na motivação da assistência às festas de candomblé -; o da análise dos diversos elementos que se combinam na indumentária e nos paramentos dos orixás, de um referencial barroco inspirado das vestes litúrgicas do catolicis- mo pré-Vaticano II até a reinvenção de enfeites africanos; e sobretudo o da visualização dos próprios mitos. Pois a apresentação das fotos tiradas no decorrer do trabalho de campo não segue apenas a ordem do xirê (sucessão usual da manifestação dos orixás ao longo da festa), mas ilustra também a diversidade das "qualidades" de cada um dos deuses, e sem dúvida o leitor afeito à freqüentação das casas-de-santo deliciar-se-á em reconhecer, no virar da página, uma forma particularmente gloriosa do seu santo-de-cabeça, ou em identificar a mise-en-scène sagrada de um mito que lhe seja particularmente caro, como o de Xangô carregando o pai nas costas...

Mesmo porque, além de todos os brilhantes aspectos acadêmicos e etnográficos do livro, Mitologia dos orixás é também, claramente, a expressão de uma vivência religiosa, nesse jogo de segredo ao mesmo tempo revelado e disfarçado que, com a sabedoria aprendida nos próprios terreiros, Reginaldo Prandi coloca, desde as suas primeiras palavras, sob a proteção do Senhor da Transformação, fiador da comunicação entre todas as dimensões do mundo e entre todos os seres que nele vivem, sejam homens ou deuses.

\section{MONIQUE AUGRAS é professora titular da Pontifícia Universidade Católica do Rio de Janeiro (PUC-RJ).}




\section{Promessas e limites da democracia deliberativa}

John S. DRYZEK. Deliberative democracy and beyond: liberals, critics, contestations. Oxford, Oxford University Press, 2000. 196 páginas.

\section{Luis Felipe Miguel}

Na teoria democrática das últimas décadas, é visível a ampliação da influência das vertentes deliberativas. Com sua ênfase nos aspectos discursivos do processo político - e a visão normativa associada da participação de todos no debate como critério de legitimidade -, os chamados "deliberacionistas" ocupam hoje o lugar central nas discussões sobre o significado da democracia. De diferentes formas, estão vinculados à corrente nomes como James Bohman, Joshua Cohen, Iris Marion Young, Amy Gutmann, John Rawls e Cass Sustein, além do seu principal inspirador, Jürgen Habermas. Fundada na tradição da teoria crítica, a democracia deliberativa tornou-se a principal alternativa à visão liberal-pluralista hegemônica (em vez da defesa da participação direta e da democracia industrial, que estiveram em voga nos meios radicais dos anos 1960 e 1970). Mais importante ainda, ela é levada em consideração pelos próprios expoentes da percepção hegemônica, que se vêem obrigados a refutá-la ou, como ocorre cada vez mais freqüentemente, a incorporá-la em suas próprias construções teóricas.

Em Deliberative democracy and beyond, John Dryzek, professor da Universidade de Melbourne, ele próprio um "deliberacionista" de primeira hora, expõe os impasses atuais da corrente. Segundo o autor, a teoria democrático-deliberativa está perdendo seu impulso crítico, sendo incorporada como um aspecto a mais dentro do constitucionalismo liberal. Com isso, o projeto original de radicalização das instituições democráticas, aproximando-as do ideal de autonomia como produção coletiva das normas sociais, perde terreno para uma acomodação com o status quo dos países avançados, em que se acrescem apenas novos requisitos formais de legitimidade. A crítica de
Dryzek é convincente e a revisão que faz da literatura sobre o tema, muito útil. Mas seu livro é também uma demonstração eloqüente de que não há solução para o impasse dentro dos marcos da teoria deliberativa. Sua proposta de resgate dos aspectos críticos e emancipatórios do deliberacionismo acaba esbarrando em limites similares àqueles que condena em outros autores.

Numa formulação um tanto ingênua, mas que captura alguns dos aspectos essenciais da corrente, a democracia deliberativa exige que as decisões políticas sejam tomadas por aqueles que estarão submetidos a elas, através do "raciocínio público livre entre iguais” (Cohen, 1998, p. 186). Participação de todos, argumentação racional, publicidade, ausência de coerção e igualdade são os valores que devem balizar as tomadas de decisão em regimes democráticos. A ausência de qualquer um deles compromete a legitimidade dos resultados. Embora, à primeira vista, os ideais da democracia deliberativa dêem pouco motivo para polêmica, fica a questão de sua relevância para as sociedades reais, com toda a desigualdade e dominação que nelas têm lugar.

Boa parte dos deliberacionistas atuais, segundo Dryzek, parece acreditar que a batalha pela implantação (ou aprimoramento) dos mecanismos de democracia deliberativa gira em torno de mudanças constitucionais e legais. Aí reside a capitulação perante a perspectiva liberal. No entanto, os agentes de distorção da prática democrática "incluem discursos e ideologias dominantes, muitas vezes entrelaçados com forças econômicas estruturais. No mundo de hoje, a mais determinante de tais forças emana da economia política transnacional, impondo severos constrangimentos sobre o que é possível em termos tanto do conteúdo da política pública quanto do grau de democracia que pode ser tolerado na produção estatal de políticas.” (p. 21).

O deslocamento em direção ao liberalismo seria perceptível na obra do próprio Habermas. Quando elabora sua teoria da ação comunicativa, o filósofo alemão trabalha em tal grau de abstração que, a rigor, não é possível falar numa teoria da democracia. No momento em que ele finalmente volta sua atenção para as instituições políticas, no 
livro Direito e democracia, de 1992, verifica-se uma "reconciliação", nas palavras de Dryzek, com "fatos [pretensamente] imutáveis do mundo moderno”, vinculados à estrutura político-econômica. $\mathrm{Na}$ medida em que admite que o foco da mudança possível se restringe ao ordenamento legal, tornase difícil distinguir Habermas dos teóricos deliberacionistas liberais (p. 24).

Isso levaria Habermas, por exemplo, a estabelecer um modelo pelo qual a opinião pública gera influência, que se transforma em "poder comunicativo" através de eleições; e este, por sua vez, torna-se "poder administrativo" por meio da legislação. Dryzek observa que é, no mínimo, duvidoso se uma percepção tão estilizada do processo político será capaz de captar pelo menos uma parte de sua dinâmica real (pp. 25-26). O jogo de forças é despido de todas as suas condicionantes estruturais e o que sobra é uma versão mais sofisticada dos manuais escolares de civismo. Em suma, a aceitação acrítica da fixação de uma esfera política isolada das restantes esferas sociais é a própria capitulação diante do constitucionalismo liberal. Mas vale observar que, ao contrário do que sugere Dryzek, essa não é uma virada recente na obra de Habermas, mas um traço que já está presente em sua tese pioneira sobre a constituição da esfera pública (Habermas, 1984 [1962]).

Contra tal acomodação, Dryzek acredita que o deliberacionismo deve enfrentar os problemas colocados à democracia pelo ordenamento capitalista - o que ele mesmo fez, em obra anterior, apontando como solução possível o reforço dos mecanismos corporativos de representação de interesses (Dryzek, 1996). No entanto, em Deliberative democracy and beyond o tema nunca é explorado. O autor assinala a importância do ponto aqui e ali, e por vezes faz referência à necessidade da garantia de padrões mínimos de conforto para a incorporação de todos os cidadãos no processo deliberativo, numa solução à la Estado de bemestar social. Mas os constrangimentos que a propriedade privada dos meios de produção (mais do que simplesmente a desigualdade econômica) impõe à livre deliberação política, no âmbito tanto do Estado quanto da vida cotidiana, ficam estranhamente ausentes do livro.
O elemento central da argumentação, então, é exposto de forma apenas abstrata: o foco principal da discussão não deve ser a democracia como tal, mas os processos de democratização. Dryzek assinala que a expressão não indica a expansão global da democracia liberal, e sim seu aprofundamento, o que incorpora três dimensões. Primeiro, a inclusão efetiva de mais pessoas ao debate público; depois, a ampliação das questões e áreas da vida sujeitas ao controle democrático; por fim, o aprimoramento da autencidade de tal controle, que deve ser mais do que meramente formal ou simbólico (p. 29). Mais uma vez, pouco há a objetar quanto a essa declaração de intenções. Mas, no nível de generalidade em que ela permanece, é difícil ver onde reside a diferença em relação às teorias prescritivas que o autor condena como sendo uma mera "esperança para um mundo melhor”, com reduzido interesse efetivo (p. 59).

Igualmente insatisfatório é o tratamento dado ao problema da organização da discussão política. Em suas primeiras versões, a teoria deliberativa concedia ao "argumento racional" o monopólio do debate: só ele teria lugar na boa discussão. No entanto, como a habilidade no uso do argumento racional é desigualmente distribuída na sociedade, a regra representaria um privilégio para determinados grupos. Isso levou alguns autores a pleitearem a aceitação de outras formas de discurso, como o testemunho, a narrativa, a retórica ou a saudação (por exemplo, Young, 2000, pp. 52-80), que favoreceriam a expressão dos grupos dominados." Por outro lado, a idéia de que a boa deliberação exige atenção exclusiva ao bem geral favorece aqueles interesses particulares que, graças às ideologias dominantes, usualmente se passam por coletivos. Contra isso, teóricos deliberacionistas têm pedido permissão para introduzir interesses parciais no debate.

Dryzek toma uma posição cautelosa em relação a esses problemas. Interesses parciais são

\footnotetext{
* No entanto, a aceitação de outras formas de discurso não resolveria a desigualdade entre os grupos sociais, já que $\mathrm{o}$ argumento racional possui uma legitimidade simbólica maior e também, é possível especular, uma eficácia maior no debate. Para uma discussão em outro contexto, mas pertinente, ver Bourdieu (1996 [1982]).
} 
admitidos, mas apenas se forem capazes de se vincular ao bem geral (p. 73). Outras formas de discurso são aceitas, mas o argumento racional deve estruturar todo o contexto do debate (p. 168). O problema do consenso, em especial, alcança uma solução bizarra. $\mathrm{O}$ autor admite que a orientação para o consenso, própria do deliberacionismo inicial, leva a exigências inalcançáveis em sociedades complexas como as contemporâneas. Porém, não está disposto a aceitar sua substituição pelo compromisso barganhado, como fazem outros (por exemplo, Elster, 1998, p. 6). Assim, chega à conclusão de que, como resultado da deliberação democrática, todos devem concordar com a decisão adotada, mas cada um por um motivo diferente (p. 170).

Diante de outros dilemas, que expõe no final do livro - discursos como o racismo devem ser excluídos a priori ? a adesão a valores de civilidade deve ser exigida com condição para o ingresso no debate? e se a barganha entre interesses egoístas se sobrepuser à reflexão sobre o interesse geral? -, a resposta é sempre a mesma: "mecanismos endógenos" à deliberação promovem o melhor resultado. Entregues à sua própria lógica, eles derrotam $\mathrm{O}$ racismo, geram a civilidade, forçam a reflexão sobre o bem comum. No mundo de faz-de-conta da teoria, ao qual Dryzek sempre volta, embora não se canse de criticá-lo, já está tudo resolvido. Mas quando fechamos o livro e olhamos em torno, percebemos que pouco avançamos na compreensão dos constrangimentos reais à prática democrática.

A precariedade das conclusões de Dryzek está ligada a um equívoco de origem, que marca toda sua abordagem. A confluência entre o deliberacionismo e o constitucionalismo liberal não é um acidente de percurso, mas um efeito de similaridades profundas entre as duas vertentes. Conforme observou certa vez Atilio Boron (1995, p. 72), no pensamento liberal impera a visão de "um 'céu político' completamente independentizado da base material”. Na teoria democrático-deliberativa, tal céu é discursivo. Sem uma ruptura com o idealismo que subjaz a essa concepção, qualquer crítica à "democracia realmente existente" fica comprometida. Nesse sentido, apesar de todas as suas limitações, a corrente "participacionista" dos anos 1970, com a ênfase que dava aos constrangimentos materiais à participação política, abriu uma via bem mais promissora. Sem a recuperação desse legado teórico, dificilmente o deliberacionismo terá como sair da encruzilhada em que se encontra e renovar seu compromisso crítico.

\section{Referências bibliográficas}

BORON, Atilio. (1995), "A sociedade civil depois do dilúvio neoliberal", in Emir Sader e Pablo Gentili (orgs.), Pós-neoliberalismo: as políticas sociais e o Estado democrático, São Paulo, Paz e Terra.

BOURDIEU, Pierre. (1996 [1982]), A economia das trocas lingüisticas: o que falar quer dizer. São Paulo, Edusp.

COHEN, Joshua. (1998), "Democracy and liberty", in Jon Elster (ed.), Deliberative democracy, Cambridge, Cambridge University Press.

DRYZEK, John S. (1996), Democracy in capitalist times: ideals, limits and struggles. Oxford, Oxford University Press.

ELSTER, Jon. (1998), "Introduction", in Jon Elster (ed.), Deliberative democracy, Cambridge, Cambridge University Press.

HABERMAS, Jürgen. (1984 [1962]), Mudança estrutural da esfera pública. Rio de Janeiro, Tempo Brasileiro.

(1997 [1992]), Direito e democracia: entre facticidade e validade. 2 vols. Rio de Janeiro, Tempo Brasileiro.

YOUNG, Iris Marion. (2000), Inclusion and democracy. Oxford, Oxford University Press.

\section{LUIS FELIPE MIGUEL é professor do Departamento de Ciência Política da Universidade de Brasília (UnB).}




\section{Roger Bastide e o Brasil}

Fernanda Arêas PEIXOTO. Diálogos brasileiros: uma análise da obra de Roger Bastide. São Paulo, Edusp/FAPESP, 2000. 224 páginas.

\section{Guilherme Simões Gomes Jr.}

Fernanda Peixoto é uma das antropólogas da nova geração que se tem voltado para a investigação da própria comunidade à qual pertence, em um esforço de reflexão mais do que necessário. Diálogos brasileiros é seu último trabalho sobre a história das ciências sociais no Brasil, particularmente no que diz respeito ao papel dos professores e pesquisadores estrangeiros que passaram por São Paulo, desde os anos 30. Antes, já havia publicado em revistas e obras coletivas uma série de artigos importantes para este campo de estudos, entre os quais se destacam "Franceses e norteamericanos nas ciências sociais brasileiras, 19301960" (in Sergio Miceli, org., História das Ciências Sociais no Brasil, 1989) e "Lévi-Strauss no Brasil: a formação do etnólogo" (Mana, 4, 1998).

Dentre os participantes da "missão francesa" trazida ao Brasil na época da fundação da Universidade de São Paulo, Roger Bastide (1898-1974) talvez não tenha tido a notoriedade que Claude Lévi-Strauss ou Fernand Braudel obtiveram posteriormente, por suas contribuições à Antropologia e à História Social. Mas, do ponto de vista brasileiro, não há dúvida que Bastide foi bem mais importante: primeiro, porque ficou aqui por 16 anos (19381954), ao passo que os dois outros restringiram-se a uma temporada mais curta (1935-1938); segundo, porque estudou o Brasil; e, por fim, porque dialogou intensamente com as tradições locais e teve um papel formador decisivo para os hábitos intelectuais dos estudantes brasileiros que substituíram os professores franceses quando de seu retorno.

Pode parecer estranha a afirmação de que Bastide se destaca por ter estudado o Brasil, por oposição a Lévi-Strauss, autor do tão famoso Tristes trópicos. Mas, se acompanharmos as reflexões de Fernanda Peixoto no artigo sobre Lévi-Strauss citado mais acima, poderemos perceber que o ilustre antropólogo não teve como alvo privilegiado de seus estudos propriamente o Brasil, mas os povos tribais que aqui existiam antes e independentemente da colonização portuguesa que deu origem ao que hoje se entende por Brasil. Lévi-Strauss foi antes de mais nada um americanista, como outros antropólogos franceses de sua geração foram africanistas. Por minha própria conta, arriscaria dizer que para Lévi-Strauss o Brasil era quase como um estorvo, a despeito das tardias saudades que eventualmente possa ter suscitado. Indício dessa disposição é o quanto o antropólogo evoca, em Tristes trópicos, o sonho de poder ter estado aqui no século XVI, quando o Brasil não passava de uma vaga ficção de cartógrafos e cronistas europeus.

Brasil, civilização brasileira, dinâmico processo histórico de encontros culturais, este foi propriamente o interesse de Roger Bastide, antropólogo, sociólogo, poeta, admirador dos místicos, utopista. E não se trata apenas de tomar tudo isto como objeto de ciência, mas, fundamentalmente, como trajetória de vida. Porque o Brasil foi sendo tecido por interlocuções brasileiras na carreira de Bastide. Mário de Andrade, Sérgio Milliet, Gilberto Freyre, Florestan Fernandes foram nomes decisivos na formação intelectual do professor francês. E são os diálogos com estes personagens que o livro de Fernanda busca reconstituir.

Não é descabido pensar que nessa história houve quase uma inversão. Bastide veio aqui para ensinar, o que não deixou de fazer com muito êxito, mas acabou por aprender, e muito, com esses notáveis artífices do pensamento brasileiro. Se a USP teve o sentido de constituir um novo padrão de pesquisa científica que deixasse para trás o impressionismo dos velhos bacharéis e homens de letras que haviam estudado o Brasil até então, a atuação de Bastide foi surpreendente, pois esteve baseada não na idéia de um corte com o passado, mas em uma criativa maneira de articular as antigas contribuições locais com as novas rotinas de produção de conhecimento.

Nos relatos de seus alunos dos primeiros anos em que aqui esteve, quase sempre é destacada a surpresa daqueles jovens, ansiosos pelas últimas novidades européias, diante das recomendações do professor, que insistia em trazer para o 
debate a bibliografia brasileira sobre os mais variados temas. E, nesse sentido, a relação de Bastide com o modernismo paulista foi fundamental, por dois motivos: primeiro, porque o grande autodidata que foi Mário de Andrade já tinha estabelecido uma rica pauta de estudos sobre arte, folclore, música, literatura, articulando tudo isto à religião e às relações raciais; segundo, porque Mário entre todos foi o que levou mais longe a idéia de que a tarefa de sua geração era conhecer o Brasil. Neste sentido, pode-se dizer que os caminhos em direção a Minas Gerais e ao Nordeste trilhados por Bastide já haviam sido parcialmente desbravados por Mário.

E o mesmo se deu com Gilberto Freyre, que também teve estreitas relações com os modernistas de 22. Para o francês que já havia escrito sobre Proust, Gide e a obra poética dos grandes místicos, e que advogava um lugar para a poesia no método sociológico, o encontro com o autor de Casagrande \& senzala não poderia ter sido menos auspicioso. Afinal de contas, a despeito de qualquer consideração sobre as idéias lusotropicalistas do sociólogo pernambucano, também ele admirador de Proust, não há como arrefecer o fascínio pela "livre fantasia" e a brilhante exposição literária de seu mais famoso livro. Além disso, a presença da África no Brasil, tema central da obra de Bastide, já havia sido esquadrinhada por Freyre.

Mas se, em parte, o programa de estudo sobre a especificidade da cultura brasileira conduzido por Bastide já estava presente em Freyre, o professor francês dará outras soluções interpretativas àquilo que o sociólogo pernambucano resolve colocando ênfase na mistura, no equilíbrio dos contrários e na democracia racial.

O que Fernanda Peixoto mostra em detalhe é que Bastide opõe à idéia de sincretismo como mistura o conceito de sincretismo como mosaico, que implica a "coexistência de objetos discordantes". E que o fato, por exemplo, de se ter estabelecido a correspondência de deuses africanos e santos católicos deriva não da assimilação dos contrários, mas de uma necessidade dos escravos de dissimularem suas crenças aos olhos dos brancos: uma forma de resistência, portanto. Submetidos, mas ao mesmo tempo colocados à margem da sociedade, os africanos no Brasil teriam criado "ilhas culturais". Conceito que, por sua vez, foi também motivo de controvérsia, nos anos 70, quando os novos intérpretes das religiões africanas no Brasil criticaram o mestre francês, acusando esta operação mental de propugnar uma pretensa pureza dos candomblés, derivados do "modelo nagô", por oposição à umbanda, vista como forma degenerada. O que faria de Bastide um herdeiro acrítico da tradição "romântica" que remonta a Nina Rodrigues.

Também esta interpretação da obra de Bastide é questionada por Fernanda Peixoto. Bastide tinha clareza sociológica suficiente para entender que uma cultura nunca permanece a mesma quando sua base morfológica é rompida, o que ocorreu com a escravização e o translado para o Brasil, e que a "ilha africana" não corresponde à África original mas é um processo de recriação repleto de lapsos. A "ilha” não é, portanto, um isolado mas aquilo que resultou da especificidade dos contatos culturais. Tampouco pode ser vista sob a ótica da permanência, mas deve ser entendida como um processo de busca que o africano realiza em certas condições: no campo, pelo fato de ter sido mantido em espaços reduzidos e separado do mundo dos brancos; na cidade, porque ela é mesmo propícia à criação de nichos, onde proliferam os batuques, as confrarias, as práticas religiosas.

E o mais interessante do livro de Fernanda Peixoto é que ela mostra como Bastide esteve simultaneamente ligado, por uma rede de influências recíprocas, com os dois grandes adversários na interpretação do problema racial no Brasil: Gilberto Freyre e Florestan Fernandes, seu aluno e sucessor na principal cadeira de Sociologia da USP.

Por oposição ao sociólogo pernambucano, egresso das elites e sempre simpático às soluções autoritárias, seja no Portugal salazarista ou no Brasil dos militares, Florestan, filho de uma empregada doméstica, foi obrigado a desmentir seu destino de classe apoiando-se em um árduo combate pessoal e nas nascentes instituições educacionais republicanas que propiciavam timidamente a ascensão pelo mérito. A sua atuação na USP até ser caçado pelo AI-5, em 1969, e sua obra - de início típica de um scholar mas que tendeu progressiva- 
mente para posições engajadas e radicais - marcaram decisivamente o pensamento acadêmico e a vida política de São Paulo.

No que diz respeito à questão racial, tema de pesquisa que coordenou junto com Bastide no início dos anos 50, sob encomenda da Unesco, Florestan, já claramente influenciado pelo materialismo histórico, do qual se aproximou em uma perspectiva nada dogmática, buscou entender o problema do preconceito e da discriminação como um prolongamento da escravidão, que selecionou a cor como marca social, símbolo da posição de classe na nova ordem que se instituiu sem colocar em questão o antigo poder das elites brancas.

Quanto a Bastide, parceiro no empreendimento, o que se percebe pela reconstrução do diálogo promovida por Fernanda Peixoto é que ele se afasta, então, mais um pouco das teses de Freyre, ao pressupor que se o ideal da "democracia racial" impede manifestações mais radicais de racismo, por outro lado escamoteia o preconceito por meio de barreiras ocultas que segregam e discriminam. Com isto, a solução brasileira atenua a eventualidade da revolta e cria uma espécie de ambivalência ideológica, que faz o descendente do africano oscilar entre o orgulho da própria cor e o sentimento de inferioridade que resulta da adoção do ponto de vista do branco.

Muito mais poderia ser dito desse livro que, sem muito alarde, tem a virtude de esclarecer episódios decisivos do pensamento brasileiro no século $\mathrm{XX}$. Livro que se articula a uma tradição que é tanto mais rica quando se volta para dentro, na perspectiva de um cosmopolitismo esclarecido que atrai sem receio homens e idéias estrangeiras, com a consciência de que sem instituições democráticas, sólidas rotinas intelectuais, atitude crítica, e o estudo da própria realidade, os homens podem ser amáveis, as idéias sedutoras, mas tudo isso se dissolve, porque o local continua o mesmo, sempre sujeito a todos os caprichos dos dominantes da hora.

\section{GUILHERME SIMÕES GOMES JR. é professor de Antropologia da Pontifícia Universidade Católica de São Paulo (PUC-SP).}

\section{A conexão eleitoral de uma familia política carioca}

Karina KUSCHNIR. O cotidiano da política. Rio de Janeiro, Jorge Zahar Editor, 2000. 162 páginas.

\section{Jairo Nicolau}

Ao longo da década de 1990, muitos cientistas políticos dedicaram-se ao estudo do Poder Legislativo no Brasil. Diversos trabalhos empíricos ajudaram a conhecer diferentes dimensões da atividade parlamentar: o padrão da produção legislativa, a disciplina partidária, o trabalho das comissões permanentes e a relação com o Poder Executivo. Esses trabalhos, em geral, privilegiaram uma abordagem endógena (estudo da organização interna do Legislativo). Um tema praticamente negligenciado pela Ciência Política brasileira é o da relação entre os parlamentares e o eleitorado. Afinal, como os senadores, deputados federais e estaduais e vereadores relacionam-se com seus eleitores? Sabemos que, por injunções de nosso sistema eleitoral, os parlamentares precisam cultivar uma relação permanente com sua "base eleitoral", seja ela territorial, profissional, ideológica ou "de identidade". Mas ainda conhecemos muito pouco acerca das diversas formas de relacionamento entre os representantes e os representados no país.

Menosprezada pela Ciência Política, a conexão eleitoral (termo que designa a relação entre os parlamentares e o eleitorado) é tema de interesse crescente por parte da Antropologia. O livro $O$ cotidiano da política, da antropóloga Karina Kuschnir, é, provavelmente, a tentativa mais ambiciosa de descrever a atividade de um parlamentar na arena extralegislativa. $\mathrm{O}$ trabalho descreve o cotidiano de uma família de políticos (pai deputado, filha vereadora) de um bairro do subúrbio da cidade do Rio de Janeiro. O pai começou sua atividade parlamentar em 1962 e a filha, sua herdeira política, trinta anos depois, em 1992. Mas o livro privilegia a atuação parlamentar da vereadora e nos apresenta uma descrição detalhada de sua rotina. 
O mandato da vereadora se organiza como um típico mandato de serviços, com uma atuação prioritariamente de intermediação entre as demandas populares e o governo. $\mathrm{Na}$ concepção da família estudada, fazer política é ter acesso privilegiado aos órgãos públicos e com isso poder atender à comunidade: "[...] a conquista de acessos, ou a entrada para a política, é resultado da colaboração dos membros de uma rede em uma série de trocas. Votos, cargos, indicações, pedidos de promoção, interferência em processos burocráticos e legais, encaminhamento de pedidos são os principais recursos de que os Silveira dispõem para trocar com os membros de sua rede. Em contrapartida, recebem financiamentos, bens materiais $\mathrm{e}$ ajuda em forma de trabalho na campanha. Esta é a base que constitui o sistema de dar, receber e retribuir acessos.” (p. 105).

Sou daqueles que acredita que livro não é tese. Por isso, penso que livros cuja matriz foi uma tese devem se livrar de algumas marcas que, se fazem sentido para um trabalho apresentado academicamente, são dispensáveis em trabalhos destinados a um público mais amplo: notas extensas, referências bibliográficas em excesso, evidências de erudição para além da conta. O livro de Karina Kuschnir, originalmente uma tese de doutorado defendida no Programa de Pós-Graduação em Antropologia Social (PPGAS) do Museu Nacional em 1998, parece ter a preocupação de justamente não aparecer como um livro acadêmico. A começar pelo título seco, sem os subtítulos tão comuns, como por exemplo: a atividade política de uma família do subúrbio do Rio de Janeiro. Não há o inevitável capítulo teórico (quase sempre uma revisão bibliográfica do tema tratado) de abertura. Além de um texto limpo e elegante, as notas são parcimoniosas e até os agradecimentos aparecem apenas ao final do livro. Enfim, nada para espantar o leitor menos especializado.

Mas, apesar da descrição tão rica e reveladora feita pela autora (e talvez por isso), acabei sentindo falta de uma discussão mais aprofundada de como o caso apresentado ajuda a compreender aspectos fundamentais do sistema político e das relações sociais no país. Um tema óbvio é o do clientelismo. O termo tem um sentido pejorativo no meio polí- tico e acadêmico e a autora é muito cuidadosa e não condena o tipo de ação política da família estudada. Apenas na antepenúltima página do livro Karina critica as mazelas do clientelismo na política brasileira, lembrando que relativizar não é valorizar positivamente: "o clientelismo é, sem dúvida alguma, uma prática perversa dentro do sistema democrático, sobre o qual se baseiam as instituições políticas brasileiras. Muitas das mazelas do país devem-se à falta de percepção dos direitos e deveres da cidadania por parte da população e, principalmente, dos políticos que ocupam diversas esferas do poder público. Desse ponto de vista, são particularmente nocivos aqueles que, como os Silveira, promovem uma relação de solidariedade vertical com seus eleitores, ignorando práticas de organização e reivindicação de demandas coletivas típicas da cultura cívica.” (p. 143).

A conexão eleitoral no Brasil é profundamente marcada pelos mandatos de serviço. Os parlamentares desenvolvem redes de atendimento para os seus eleitores. Alguns montam sistemas de atendimento prioritariamente privados, mas a maioria serve de intermediários entre suas comunidades e o Poder Executivo. Apesar da inexistência de estudos aprofundados sobre o tema, as evidências são de que quanto mais se desce na estrutura federativa e no tamanho do município, mais tende a ser predominante o padrão do parlamentar como intermediador de interesses. Não é por outra razão que a família estudada tem pânico da intermediação política de organizações concorrentes: associações de moradores e partidos políticos. Aliás, pelo relato pode-se observar que partido é uma instituição absolutamente secundarizada na atividade política da família.

$O$ cotidiano da política teve o mérito de abrir a caixa-preta da conexão eleitoral no Brasil. Com sua leitura, aprendemos muito sobre o que faz um parlamentar cujo mandato é dedicado, prioritariamente, a captar demandas de uma comunidade geograficamente definida e a tentar resolvê-las via a ação do Poder Executivo. Existem outras formas de relação entre representados e representantes: a intermediação via o mundo organizado dos parlamentares do PT, a representação ideológica do parlamentar com votação difusa, o mandato a 
serviço de organizações e lobbies. Outras pesquisas ajudarão não só a descrever essas outras formas de relação entre representantes e representados, como a mensurar a incidência de cada uma no sistema representativo brasileiro.

JAIRO NICOLAU é professor de Ciência Política do Instituto Universitário de Pesquisas do Rio de Janeiro (Iuperj).

\section{Elites ou lobbies: quem formula as políticas publicas brasileiras?}

Eduardo Cesar MARQUES. Estado e redes sociais: permeabilidade e coesão nas políticas urbanas no Rio de Janeiro. Rio de Janeiro/São Paulo, Revan/ FAPESP, 2000. 352 páginas.

\section{Celina Souza}

Como se elaboram e implementam as políticas públicas no Brasil? Como as relações entre o público e o privado se desenvolvem na arena decisória das políticas públicas? Como se articulam os interesses dos indivíduos, servidores públicos, empresas privadas, comunidades profissionais e organizações estatais na determinação das políticas públicas? Como entender as regras e os resultados do aparentemente nebuloso mundo das licitações de obras públicas?

Essas questões são enfrentadas com competência, clareza e sofisticação teórica e metodológica por Eduardo Cesar Marques no livro Estado e redes sociais, que resulta de sua tese de doutorado defendida na Unicamp. Por meio da análise de uma política pública - a de saneamento básico - em um determinado espaço territorial - a Região Metropolitana do Rio de Janeiro - e em um período dado - 1975-1996 - sua pesquisa ilumina o nosso entendimento sobre processos e fenômenos mais gerais e de conseqüências analíticas mais abrangentes, abrindo também novas interpretações que nos ajudam a compreender melhor um processo complexo como a formulação e a implementação das políticas públicas em geral. Além de permitir leituras inovadoras sobre um campo do conhecimento ainda muito pouco explorado no Brasil - o das políticas públicas -, o autor generosamente divide com o leitor os caminhos metodológicos que seguiu - o da construção e análise de redes sociais.

O livro está estruturado em três partes e oito capítulos. Entre os seus inúmeros méritos destaco os seguintes. No capítulo 1 o leitor encontrará uma extensa bibliografia sobre os principais temas abordados, principalmente a literatura sobre estudos urbanos e a de redes sociais. Não se trata, todavia, de 
uma revisão da literatura sobre esses temas, mas de um diálogo com essa literatura e de uma discussão acerca das vantagens do uso da metodologia de redes sociais para estudos sobre processos decisórios. Essa metodologia, tributária da teoria das elites, tem sido pouco utilizada no Brasil. Embora alguns trabalhos se proponham a analisar determinado fenômeno político ou social pela ótica da teoria das elites, ainda não se difundiu entre nós o uso do método gerado por essa teoria. Esse método torna possível a construção de matrizes capazes de mapear os diversos vínculos que se estabelecem entre os vários atores - individuais, de grupos e institucionais - que participam de uma determinada decisão, a qual se transforma em política pública. Como Eduardo Marques nos mostra, as ligações desses atores geram vínculos - institucionais, políticos e de amizade -, formando as redes sociais que se constituíram ao longo do período analisado em torno da política de saneamento básico da Região Metropolitana do Rio de Janeiro. A pesquisa mostrou que as redes sociais construídas ao longo do tempo em torno dessa política regulam a relação entre a burocracia técnica, políticos, ocupantes de cargos nas empresas estatais e empresas privadas contratadas pelo setor. Todos os passos do método foram detalhados pelo autor no Anexo 3.

O segundo aspecto que merece destaque é o questionamento de certos mitos correntes nas análises sobre políticas públicas no Brasil. Um desses mitos é o de que, durante o regime militar, as políticas públicas subnacionais eram meras reproduções das políticas nacionais. $\mathrm{O}$ autor demonstra a enorme margem de manobra das elites envolvidas na determinação da política de saneamento básico regional e onde a dinâmica política local e estadual teve papel crucial na determinação dessa política, inclusive reformulando aspectos importantes da política tarifária.

Outro mito enfrentado, e que o autor considera a maior contribuição do seu trabalho, diz respeito à visão corrente sobre a baixa institucionalização (ou privatização) do Estado no Brasil. O uso da metodologia de redes sociais permitiu visualizar que o "poder institucional, ao contrário de fraco ou inexistente, opera conjugado e articulado com o poder posicional oriundo de determinados padrões de relação pessoal e expressa a sua presença não apenas na rede da comunidade, mas também por meio da presença inegável de uma lógica institucional no cálculo dos funcionários do Estado.” (p. 23).

O terceiro mito, que é um desdobramento do anterior, é o de que as organizações públicas são frágeis diante do poder dos lobbies, especialmente em se tratando das famosas empreiteiras de obras públicas. A conclusão a que chega o autor é de que existe uma interpenetração de interesses, que ele denomina de permeabilidade, entre o público e o privado nas políticas públicas. Segundo ele, essa permeabilidade pode ser mais bem explicada como resultado da trajetória de vida dos indivíduos e das organizações na comunidade, como prega a teoria das elites, do que pelo papel dos lobbies, como nos dizem os pluralistas, ou pela via dos anéis burocráticos de poder.

Alguns dados trazidos pelo livro também merecem referência: um deles é a paulatina transformação do setor de saneamento básico, de um espaço de atuação de pequenas empreiteiras, em locus de disputa dos grandes grupos empresariais da construção civil. Aqui o autor discute a questão da corrupção, que, no entanto, como ele enfaticamente registra, não é central à sua pesquisa, nem ao seu argumento.

Há mais de três décadas, Theodore Lowi nos brindou com uma importante máxima: "a política pública faz a política” (policy makes politics). O livro de Eduardo Marques é uma tentativa bemsucedida de testar essa máxima e de começar a confirmá-la no que se refere às políticas públicas. Deve ser tomado como um marco nos estudos sobre políticas públicas no Brasil, especialmente pelo uso cuidadoso de referenciais teóricos articulados a uma metodologia ainda inédita entre nós. No caso brasileiro, esses referenciais, suas hipóteses e métodos talvez tenham poder explicativo maior do que as teorias, doutrinas e métodos usualmente utilizados nas pesquisas em ciências sociais que analisam políticas públicas, elites, relações de poder e o papel do setor privado.

\section{CELINA SOUZA é professora da Universidade Federal da Bahia (UFBA) e pesquisadora visitante do Departamento de Ciência Política da Universidade de São Paulo (USP).}




\section{Das queixas de agressões sexuais d̀ sentenças: um fluxo contínuo de disputas através da linguagem}

Joana Domingues VARGAS. Crimes sexuais e sistema de justiça. São Paulo, IBCCRIM, 2000. 224 páginas.

\section{Ana Lúcia Pastore Schritzmeyer}

Em tempos de redução de prazos para conclusão do mestrado e mesmo de estímulos para não mais se fazê-lo, incitando-se o ingresso dos alunos diretamente no doutorado, a publicação de uma versão parcialmente modificada da dissertação de mestrado que Joana Domingues Vargas defendeu, em setembro de 1997, no Departamento de Antropologia Social do Instituto de Filosofia e Ciências Humanas da Unicamp é, sem dúvida, um forte argumento a favor de se ponderar mais a respeito dessa questão.

Desde a apresentação do livro, redigida pela orientadora Alba Zaluar, até sua última página, temos mostras mais do que suficientes de quantos são os cuidados e percalços envolvidos na realização de um criterioso, denso e inédito trabalho interdisciplinar e, conseqüentemente, do quanto tal empreendimento demanda dedicação e tempo.

A proposta da pesquisadora de realizar um trabalho diferente da maioria dos estudos sociojurídicos até hoje desenvolvidos, abordando o fluxo de procedimentos e de pessoas pelas organizações que compõem o Sistema de Justiça Criminal Polícia, Ministério Público, Varas Criminais -, não fragmentando a análise de tais organizações, revela seu empenho em fazer do mestrado muito mais do que um exercício acadêmico de reprodução e aplicação de conceitos a um objeto pontual.

Partindo de narrativas de mulheres e meninas que, entre 1993 e 1994, compareceram à Delegacia de Defesa da Mulher (DDM) de Campinas para relatar agressões sexuais das quais se declaravam vítimas, Joana Vargas analisa a complexa transformação dessas narrativas em queixas, tipificadas em boletins de ocorrência como delitos de estupro (tentado ou consumado), atentado violento ao pudor ou sedução; das queixas em inquéritos policiais; dos inquéritos em denúncias e dessas em processos com seus respectivos desfechos.

Mais do que um fluxo de procedimentos policiais e judiciais, o que o livro revela é um fluxo contínuo de disputas através da linguagem. Linguagem oral, gestual, escrita ou silenciosa que vai articulando diferentes tipos de conhecimento senso comum, paradigmas construídos no ambiente organizacional, preceitos presentes nos códigos -, os quais permitem a interpretação de situações, a categorização de pessoas e cenas, a elaboração de relatos e descrições.

Com base em dados qualitativos - trechos de narrativas e de boletins de ocorrência - e quantitativos - números de boletins, inquéritos, denúncias e sentenças encontrados na DDM de Campinas e no Fórum local -, a pesquisadora nos mostra que não apenas acordos e entendimentos, mas também evidências e fatos são construídos nas interações entre os diversos agentes das organizações do Sistema de Justiça Criminal e entre esses e vítimas, suspeitos e testemunhas envolvidos. Sendo construções resultantes de interações, tais evidências e fatos estão sujeitos a elaboração, negociação e argumentação, fazendo com que disputas tidas como orientadas para a busca de fatos se revelem disputas em torno de outros alvos. As narrativas originais são descontextualizadas, reordenadas de forma a assumir um caráter objetivo e universal para, posteriormente, serem reutilizadas e "compreendidas".

A pesquisa bibliográfica empreendida pela autora é diligente, bem focada, resultando, ao longo de todo o texto, na articulação e no uso pertinentes de discussões teóricas atuais e imprescindíveis no campo em que se encontram a Antropologia, a Sociologia e o Direito.

As menções às experiências do trabalho de campo e à construção do texto antropológico capítulos 1 e 2 - denotam paciência, obstinação, envolvimento e sensibilidade em relação ao objeto, sem prejuízo do rigor científico que pauta a coleta e a interpretação dos dados. É exemplar a 
etnografia que Joana constrói dos espaços da Delegacia de Defesa da Mulher, onde, durante meses, acompanhou o trabalho de policiais e os depoimentos de vítimas, suspeitos e testemunhas.

A discussão antropológico-jurídica sobre as causas e consequiências da prisão durante o andamento do processo penal - capítulos 3 e 4 demonstra o caráter realmente interdisciplinar do trabalho. Nessas páginas, são tratadas e articuladas tanto questões jurídicas - leis e suas interpretações; polêmicas entre operadores da Justiça quanto à decretação de prisão preventiva - quanto questões antropológicas - construção social de estereótipos e de bodes expiatórios; percepção e funcionamento de lógicas classificatórias e hierarquias; a vingança como ritual etc. Leitores de exclusiva formação jurídica e outros de exclusiva formação antropológica aqui compartilharão várias questões de interesse comum.

A descrição da pesquisa propriamente dita capítulo 5 -, do estado em que as informações foram encontradas e de como elas se transformaram em dados passíveis de sistematização e interpretação retrata um trabalho metodológico cuidadoso e criativo.

Nos dois últimos capítulos, certos dados são aproveitados em análises específicas referentes à cor dos suspeitos e à natureza e grau de relacionamento entre agressor e vítima dos crimes em questão. Novamente articulando conhecimento antropológico e jurídico, a pesquisadora demonstra e conclui que o Sistema de Justiça Criminal, permeável a valores e concepções presentes na sociedade, pune mais réus negros e culpabiliza mais os suspeitos aparentados das vítimas, especialmente quando se trata do próprio pai.

Nas considerações finais, Joana reitera que seu livro trata, em última instância, da implementação do controle social exercido, em vários níveis, pelos diferentes atores do sistema - queixosos, policiais, testemunhas, promotores, juízes -, controle esse, portanto, influenciado pelas concepções desses atores acerca de regras sexuais, transgressões e anormalidade.

Mais uma vez buscando fazer de seu mestrado um trabalho completo, a autora nele se baseia para apontar a necessidade premente de se pensar um modelo democrático de controle social que, de fato, controle apenas os que quebram regras legais e não, indiscriminada e potencialmente, os que pertencem a certas camadas étnicas e socioeconômicas da população. O que, segundo ela, implica investir numa mudança de mentalidade, não só dos agentes do Sistema de Justiça Criminal, mas também de diversos setores da sociedade, pois a todos cabe reivindicar igualdade de tratamento policial e judicial para qualquer cidadão.

Vale lembrar que uma das constatações da autora é a de que nas próprias DDMs, criadas com base no pressuposto de que mulheres seriam mais bem atendidas e compreendidas por profissionais do mesmo sexo, reproduzem-se preconceitos, estereótipos e tratamentos discriminatórios.

Em relação a esse ponto, parece-me que poucas, porém importantes iniciativas vêm sendo tomadas na direção de promover algumas mudanças de mentalidade no interior de determinadas instituições, como nas polícias civil e militar do Estado de São Paulo, por exemplo.

A Secretaria Estadual da Segurança Pública, onde até recentemente trabalhei, vem investindo, há pelo menos dois anos, na implementação de uma política que leve ao aumento da qualidade na produção, coleta, sistematização, uso e divulgação de dados estatísticos referentes à sua área de atuação. O preenchimento de boletins de ocorrência, por exemplo, não só é atualmente checado, com vistas à correção de lacunas indevidas e de dados mal registrados, como já está informatizado e integrado a um sistema on line, em funcionamento no Município de São Paulo - INFOCRIM -, o qual permite aos agentes da Secretaria, e mesmo a pesquisadores, incomparável rapidez e precisão no acesso a muitos dados. Todavia, para sorte dos pesquisadores, por mais perfeitas que estas estatísticas venham a ser, provavelmente nada suprirá idas a campo para a realização de análises qualitativas do processo de produção e utilização de informações. Nenhuma estatística ou sistema informatizado parece ser capaz de interpretar o uso da linguagem e as negociações sobre os sentidos do que está em jogo na produção de conhecimentos.

Portanto, cabe aos pesquisadores das ciências sociojurídicas lidar muito bem com números, 
mas melhor ainda com análises que, a partir deles, possam ser feitas, tornando-as o cerne de seus trabalhos.

A pesquisa de Joana Vargas enfrenta com coragem o desafio de trabalhar qualitativamente dados quantitativos. E um dos desdobramentos possíveis desse desafio consistiria na busca de respostas mais completas às questões da integração ou segmentação do Sistema de Justiça Criminal e das divergências ou convergências entre interpretações elaboradas por seus diversos agentes.

Nesse sentido, considero que a decisão da autora de contabilizar e analisar somente um dos boletins, quando há vários relativos ao mesmo suspeito - idem para inquéritos, denúncias e sentenças -, desprezando "repetições" de dados do suspeito, impossibilita o que seria uma espécie de "verificação controlada de discrepâncias interpretativas". Se todos os documentos referentes ao mesmo suspeito fossem considerados e comparados, poderíamos justamente verificar se registros relativos a seu perfil, elaborados por agentes diversos, repetem-se ou não, como, por exemplo, o registro da cor da pele.

Voltando ao ponto de partida desta resenha, se depois de quatro anos de mestrado Joana concluiu um trabalho da qualidade desse que o IBCCRIM ora publica, esperamos também o melhor de sua tese de doutorado em Sociologia, a ser defendida no Instituto Universitário de Pesquisas do Rio de Janeiro (Iuperj). Afinal, maturidade intelectual também faz parte de um fluxo em que se articulam vários tipos de conhecimento, o que me parece não poder ser acelerado impunemente, em especial quando pesquisadores e seus "objetos" lidam com as vicissitudes do ser humano.

\footnotetext{
ANA LÚCIA PASTORE SCHRITZMEYER é advogada, doutoranda do Programa de Pós-Graduação em Antropologia Social da Universidade de São Paulo (USP) e diretora adjunta do Núcleo de Pesquisas do Instituto Brasileiro de Ciências Criminais (IBCCRIM).
} 